\title{
Corynebacterium diphtheriae no toxigénico
}

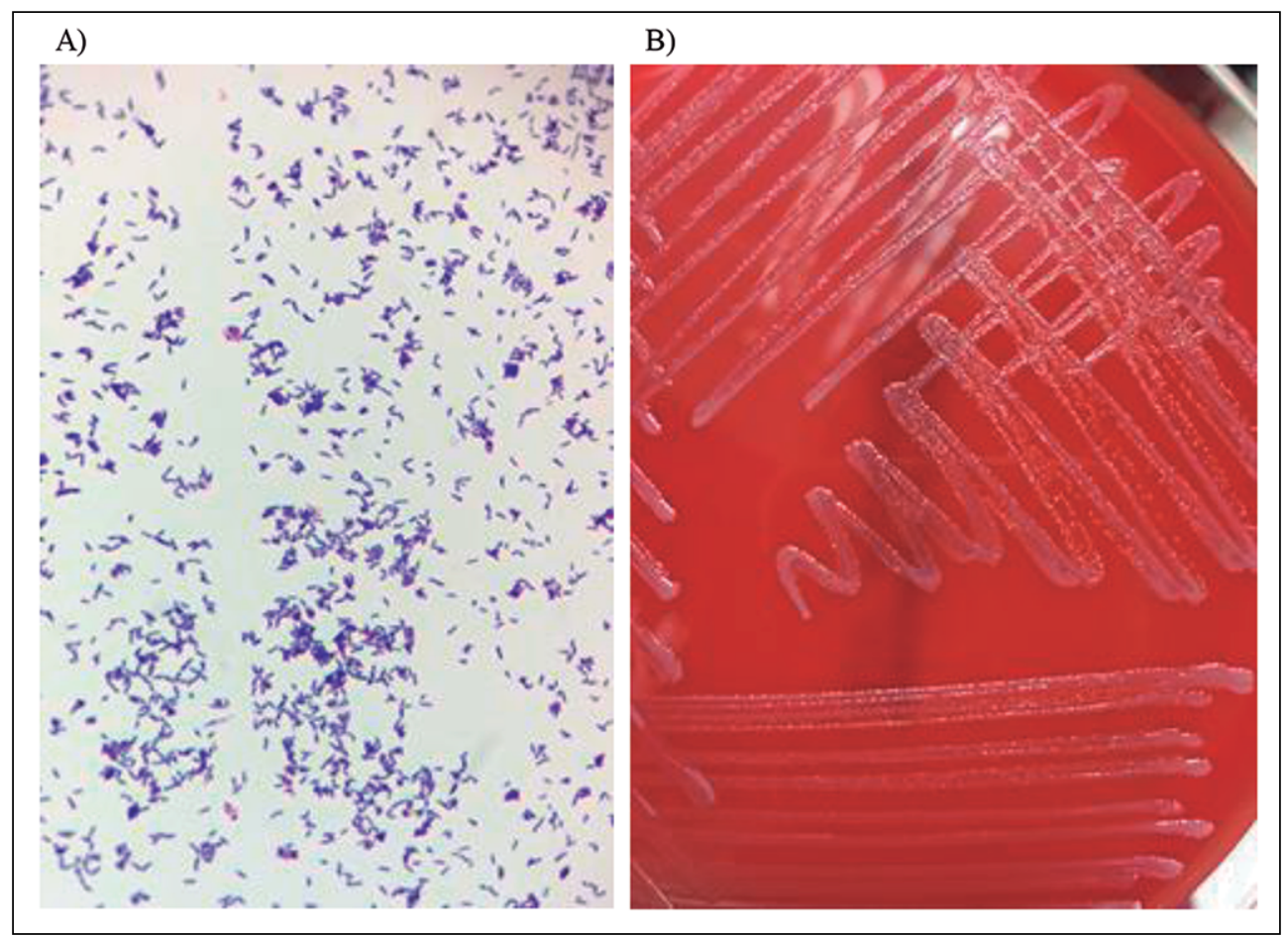

Figura 1. A) Tinción de Gram de Corynebacterium diphtheriae. B) Colonia de C. diphtheriae en agar sangre. Fotografías adquiridas en el laboratorio Microbiología de Clínica Dávila. 


\section{Corynebacterium diphtheriae no toxigénico}

La difteria es una enfermedad causada por cepas toxigénicas de Corynebacterium diphtheriae, que se ha controlado mediante la vacunación. Sin embargo, en el último tiempo han emergido cepas no toxigénicas, constituyendo un problema en salud pública y que pueden causar faringoamigdalitis, endocarditis, artritis séptica y osteomielitis. También puede producir infecciones cutáneas en pacientes con alteraciones en la piel o con inmunocompromiso.

Taxonomía: Corynebacterium diphtheriae se divide en cuatro biovares: gravis, intermedius, mitis y belfanti. La diferenciación bioquímica depende del operador, siendo la caracterización genómica más confiable. Es una especie genéticamente diversa. Especies relacionadas incluyen C. ulcerans y C. pseudotuberculosis, que causan infecciones zoonóticas en humanos.

La producción de toxina (toxigenicidad) ocurre sólo cuando el bacilo la adquiere desde un bacteriófago específico ( $\beta$-corynefago) por un proceso lisogénico, llevando la información genética de la toxina (gen tox). Las cepas toxigénicas son las que causan la enfermedad grave. Las cepas no toxigénicas por definición no contienen el gen tox, pero pueden variar en su capacidad de adherirse a la célula hospedera, en su viabilidad intracelular y en su capacidad de estimular citoquinas en el sistema inmune del hospedero, lo cual se traduce en una mayor gravedad de la infección.

Características microbiológicas e identificación: Corynebacterium diphtheriae es un bacilo aerobio, inmóvil, no capsulado. A la tinción de Gram se presenta como un bacilo grampositivo pleomórfico con estructuras claviformes similares a "letras chinas" (Figura $1 \mathrm{~A}$ ). En el caso de la difteria, el estudio debe ser orientado según la sospecha clínica. Las muestras deben sembrarse en agar sangre de cordero y agar telurito, que favorecen el crecimiento de la bacteria. En agar sangre las colonias son puntiformes y grisáceas (Figura 1 B) y en agar telurito, de color gris con centro negro. Una vez aislado debe distinguirse de otras especies de Corynebacterium que normalmente habitan la nasofaringe y la piel (Ej. difteroides). Para ello existen pruebas bioquímicas (fermentación de carbohidratos, producción de ácido láctico, entre otras), sin embargo actualmente, la espectrometría de masas por MALDI-TOF MS es de mucha utilidad. En todos los aislados de C. diphtheriae debe estudiarse la toxigenicidad. En Chile se deriva al Instituto de Salud Pública (ISP) (centro de referencia nacional).

Diagnóstico y tratamiento: Luego del diagnóstico clínico, se deben tomar muestras adecuadas (hisopado faríngeo, muestra cutánea). El uso de antitoxina va a depender si la cepa es o no toxigénica. El tratamiento se basa en eritromicina vía oral por 14 días o penicilina $\mathrm{G}$ iv o intramuscular por 10 días. Se debe tratar a los contactos con un "booster" de toxoide diftérico y antibacterianos. En cepas no toxigénicas, la investigación de los contactos debe descontinuarse.

Comentario final: Se revisita la microbiología de $C$. diphtheriae debido a la emergencia de cepas no toxigénicas, que pueden aparecer en el cultivo corriente y que causan enfermedad en pacientes de riesgo. Estas cepas deben ser estudiadas para descartar la presencia de la toxina y detener el estudio de los contactos si la cepa es no toxigénica.

Agradecimientos: A Ana Mariela Pedraza y May Manzi, pediatras de Clínica Dávila por su colaboración clínica.

\section{Referencias bibliográficas}

1.- Sangal V, Hoskisson P A. Evolution, epidemiology and diversity of Corynebacterium diphtheriae: New perspectives on an old foe. Infect Genet Evol 2016; 43: 364-70.

2.- Diphtheria. Epidemiology and Prevention of Vaccine-Preventable Diseases, $13^{\text {th }}$ Edition. Centers for Disease Control Prevention. April, 2015. https://www.cdc.gov/vaccines/pubs/pinkbook/downloads/dip.pdf

3.- Farfour E, Badell E, Dinu S, Guillot S, Guiso N. Microbiological changes and diversity in autochthonous non-toxigenic Corynebacterium diphtheriae isolated in France. Clin Microbiol Infect 2013; 19: 980-7. doi: 10.1111/1469-0691.12103.

Cecilia Tapia, Cecilia Stuardo, Rubi Troncoso y Pablo Vargas Laboratorio de Microbiología, Clínica Dávila.

Correspondencia a: Cecilia Tapia cvtapiap@gmail.com 